\title{
VIABLE SYSTEM DYNAMICS INTELLIGENT FRAMEWORK FOR ASSESSING AND OPTIMIZING SYSTEMIC REENGINEERING FOR E-GOVERNANCE ENVIRONMENTS: A CASE STUDY IN CORFU SUNSPOTS TOURIST AGENCY
}

\author{
Author(s) / Auteur(s) : \\ Nikitas ASSIMAKOPOULOS \\ Professor \\ University of Piraeus, Department of Informatics, Hellenic Society for Systemic Studies (HSSS) \\ assinik@unipi.gr \\ Alexandros MIARIS \\ Ph.D. Candidate \\ University of Piraeus, Department of Informatics, Hellenic Society for Systemic Studies (HSSS) \\ amiaris@unipi.gr
}

\begin{abstract}
Résumé :
Dealing with problems in complex environments that impede organizational cohesion, information dissemination and coordination is extremely difficult nowadays. Usage of technology without sophisticated information sharing planning and solid processes that serve with a bottom-up approach the needs of each individual within an organization, undermines time, cost and quality of deliverables.
\end{abstract}

The eG4M (e-Government for Mediterranean Countries)project basically concentrates on extending, completing and improving the e-Model through the achievement of new research results and its application by participating with the support of the Mediterranean Countries (MCs) - in establishing and consolidating their eGovernment systems.

This paper focuses on the development of a generic system dynamics model that illustrates the behavior of egovernance systems based on the VSM (Viable Systems Model) as well as the development of a web, collaborative intelligent framework that is built upon the system dynamics model. The framework is meant to have the form of a web-based simulation that is able to identify critical issues related to product, customer, information sharing and service quality using visualizations, automated analytics and impact analysis delivered with natural language format to support the systemic reengineering process, mitigate risk, predict issues during the planning phase and help the user understand complexity and inform his decisions with predictive insights.

Modeling the behavior of an e-governance system and being able to automatically process complex relationships, data and issues upon this system mitigates uncertainty at all levels, increases awareness and understanding of the real world and delivers sustainability and viability, increases growth and sets the basis for process autonomy and better coordination, controls and quality of deliverables.

Keywords / Mots-clés :

Systemic, methodologies, eG4M, VSM, e-governance 
Here we deal with the problem of Information Sharing Quality (ISQ), how it is defined and how can this problem be resolved with the use of a modern web-based simulation tool. This is done in order the agency's management to create real time scenarios and according to the results delivered to decide the best approach to its daily processes. The agency's management gains the opportunity to simulate different scenarios in advance, in order to be prepared for different business needs in advance and retain or advance the ISQ and service provided to its customers.

The System Dynamics model deals with quality and demand, assuming a perfectly competitive market, rational consumers and free entry and exit market. The simplification that factors like information sources, numbers of communication channels and number of controls that affect the quality of services provided are held constant is taken as granted. Economists argue this is a valid assumption since the weight factor in those agents is more significant than in other factors that may affect quality or demand (Downs, 1967).

In business, engineering and manufacturing, quality has a pragmatic interpretation as the noninferiority or superiority of something; it is also defined as fitness for purpose. Quality is a perceptual, conditional and somewhat subjective attribute and may be understood differently by different people. Consumers may focus on the specifications' quality of a product/service, or how it compares to competitors in the marketplace. Producers might measure the conformance quality, or the degree to which the product/service is within specifications, while others define quality as "doing the right things right". In a service organization, doing the right thing simply means balancing the two sets of expectations in the organization: the expectations of internal customer/associates (staff members and managers) and external customers (those who purchase the organization's services). The overwhelming customer demand for quality service and value product has become clear to the management of travel agents recently. Among all these customer demands, service has been increasingly recognized as a critical factor for the success of any business.

On the other hand, demand is the amount of a particular economic good or service that a consumer or group of consumers want to purchase at a given price. The demand curve is usually downward sloping, since consumers want to buy more as price decreases. Demand for a good or service is determined by many different factors other than price, such as the quality of the service provided. Along with supply, demand is one of the two key determinants of the market price.

For the travel agency's System Dynamics Model, Vensim simulation software tool has been used. After the development and the evaluation of the model in the previous chapter, it has been transferred into the Forio Online Simulation platform with the use of Vensim software where it has been braced with the implementation of scenarios, helping the user to compare the "as-is" state with the SystemicImproved state and the implementation of a visual consultant explaining to the users the results of their simulation, explaining what has gone wrong and what should be done in order to improve the current state. 
The Vensim model is illustrated in Figure 1

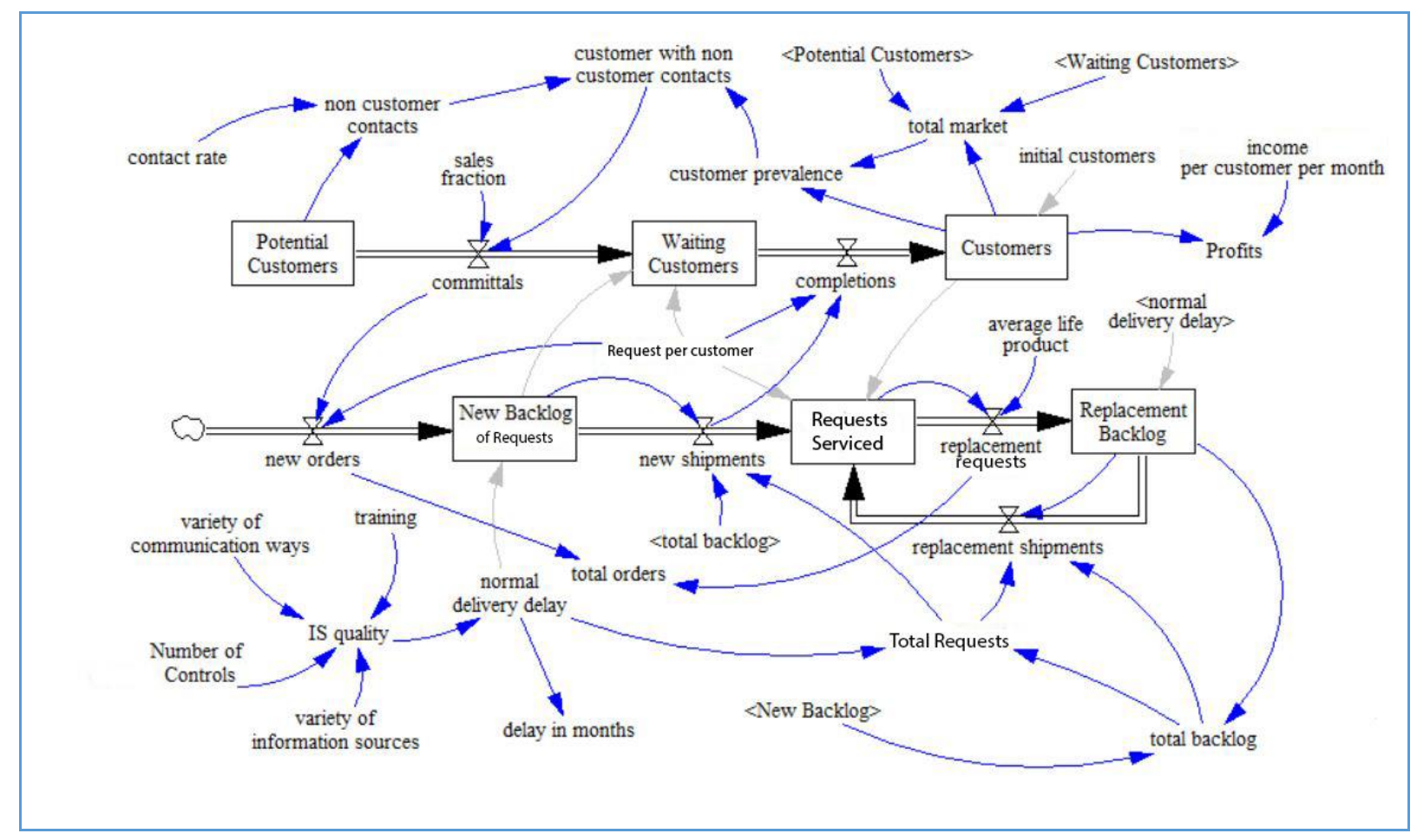

Figure 1 - Vensim Simulation Model

In the model stated in Figure 1, the way the Information Sharing quality (ISQ) - the factors that affect it are shown as well - can influence the overall quality of the product or service provided and consequently how this quality can affect the customer adoption rate and finally the profits of the organization is depicted. The factors affecting it are the variety of communications, the training, the number of controls and the variety of information resources.

Here the System Dynamics Model is separated in two main parts. The first part includes all the variables that affect the quality of the service, the ones that affect the delay, the backlog of the services (if they exist), the number of the total orders and shipments and the number of services in use. The second part (above the middle of the model) contains the variables that are related to the customers, how much they are waiting for their service, their satisfaction, the position of the organization in the market and finally its profits.

More specifically, at the first part, the four main factors that affect ISQ are depicted in the model shown on the previous chapter. The variety of the communication channels is a key factor that is directly related with ISQ. This refers to the number of possible channels that exist for the organization in order to share the proper information, like emails, mobile phones, intranet applications, face to face communication, etc. Secondly, another key factor is the number of controls that exist into the organization. The answer that defines this variable is how many controls occur from supervisors in the organization that assure that the information is being transmitted properly. Additionally, the number of the information sources is something vital to the ISQ, since in that way the number of the information providers can be defined. Last but not least, the employee training on the business processes is significant. Obviously, the larger the percentage the better for ISQ because all participants in the organization know exactly what they should do, from where they must receive information and most importantly where they have to provide it. 
ISQ affects the delay of the services provided. A delay in the provided services affect the total shipments or the number of services offered, which is another important factor that affects the whole model (Figure 1). The services offered are also affected by the number of the backlogged requests.

Total backlogged requests also influence the new requests to be served. The shipping and backlog factors are summed in a loop estimating how the orders, the backlogs, the new requests to be served, the different products in use and the replacement backlogged are being affected. Looking at the relationship between the new orders and the total requests, the delay is caused because new orders affect the backlog or the new provided services. As a result, the Services/Products the agency can provide are changed and finally there is an effect in the replacement backlog which affects the products in use and the total backlog.

The second major part of the model is consisted of the factors - variables and decision inputs - that represent customers, their behavior and adaptability and finally the profits that the organization should gain from their sales. In the customers section, both the existing and the potential customers are being researched, in terms of their acquisition, the market and how they affect the total profits.

The first decision input is the contact rate, which indicates how many contacts on average a customer has on a daily basis. This has a direct effect on the variable of the non-customer contacts which also affects the number of the customers with no customer contacts. The latter variable, is also being affected by the percentage of the customer's prevalence.

In addition, the author adds in the model a list of variables that are related with the market share. All those variables, such as the total market and the customer prevalence are affected by the second dynamic flow which the model included, the flow of transforming the potential customers to actual customers. It depicts the number of the potential customers who are connected with the sales fraction, the achieved sales and the committals of each customer. An additional important factor for the dynamic character of the model is the number of the achieved completions. It results to the estimation of the sum of the actual customers.

The latter number of actual customers can offer an insight on the percentage of the total market of the agency's customers. The total market variable is being calculated by the number of the potential customers, the number of the waiting customers and the number of the actual customers. According to this calculation, the customer prevalence indicates the rate of the customers that are being converted from potential customers of the total market to actual customers of the agency.

Finally, one of the most important functions calculated is the profit of the organization. The most important factors affecting the profits and the viability of an organization derive from the information sharing flow. These are the number of the products that are backloged, the initial customers and their contact rate to the percentage of the total market of the organization, which is clearly presented by the dynamic character of all those variables and their interdependencies. It is easy to understand how a small change to a factor can influence an important variable and if not immediately then over time. 
In order to add value to the systemic consultants and change the management initiatives using the system dynamics model, a multiplayer web simulation is developed to deliver a better analysis and user experience. The simulation has been built using the FML macro-language and the Forio Simulations Web Framework.

The structure of the application follows the same user interface framework with any other modern website - more or less - adjusted to the needs of the simulation context. The user is able to access details about the approach and read a manual about the right way to use the simulation and get the most out of it (Figure 2).

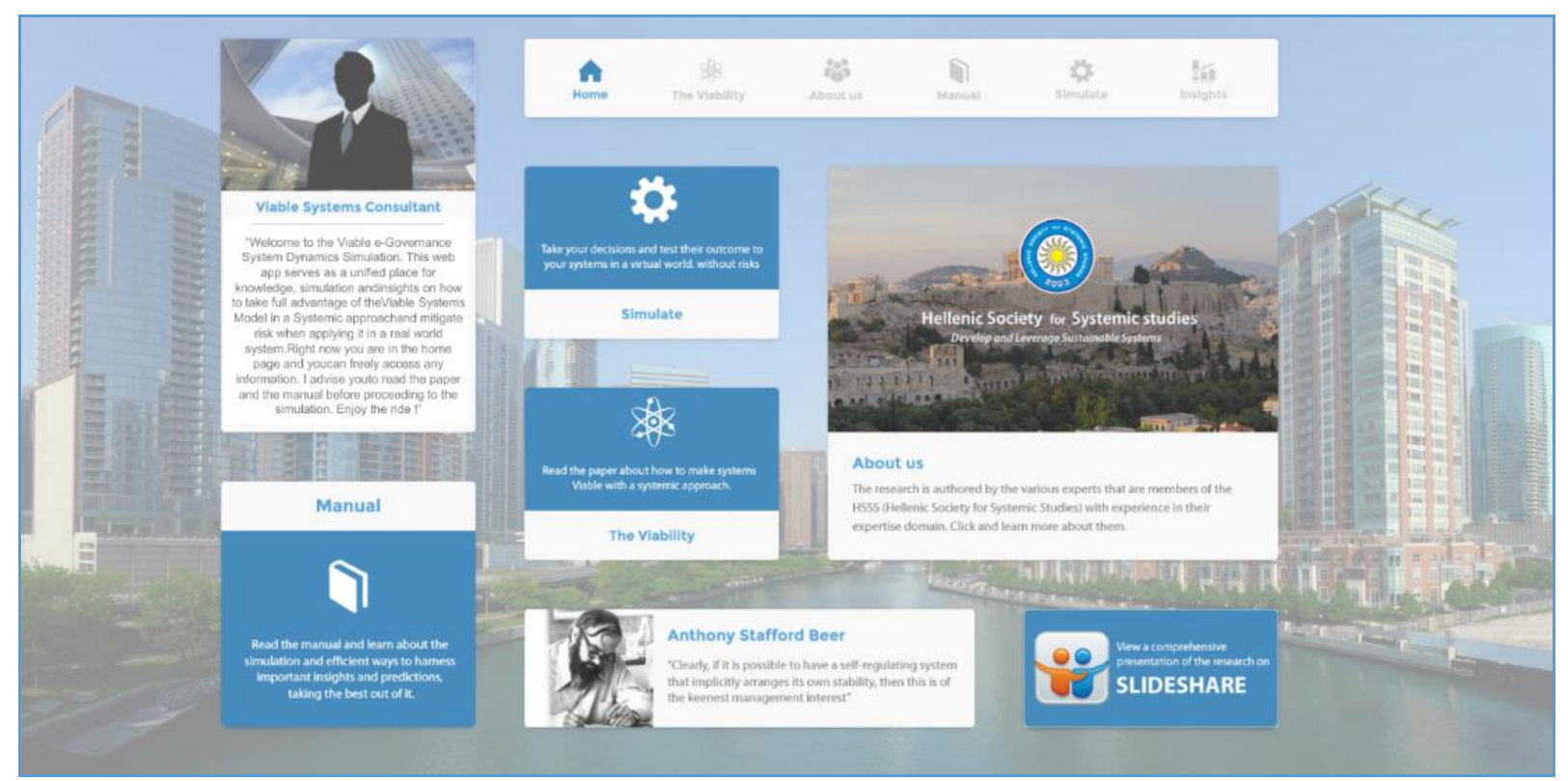

Figure 2 - Web-Based Simulation homepage

The simulation starts with the simulation settings, where users are called to take their decisions and test them in the long run. There are no risk enhancements, just a virtual environment to predict and understand how the system reacts under specific decisions and scenarios. The decisions are actual system inputs in the four (4) core areas of interest correspondingly related to: (a) Product, (b) Customers, (c) Information Sharing and (d) Sales, with the ability to compare it with different scenarios, assuming - or not - that a VSM has been implemented within the evaluated systems. Each simulation run can be saved as a scenario and be used in future simulation runs for comparison reasons (Figure 3). 


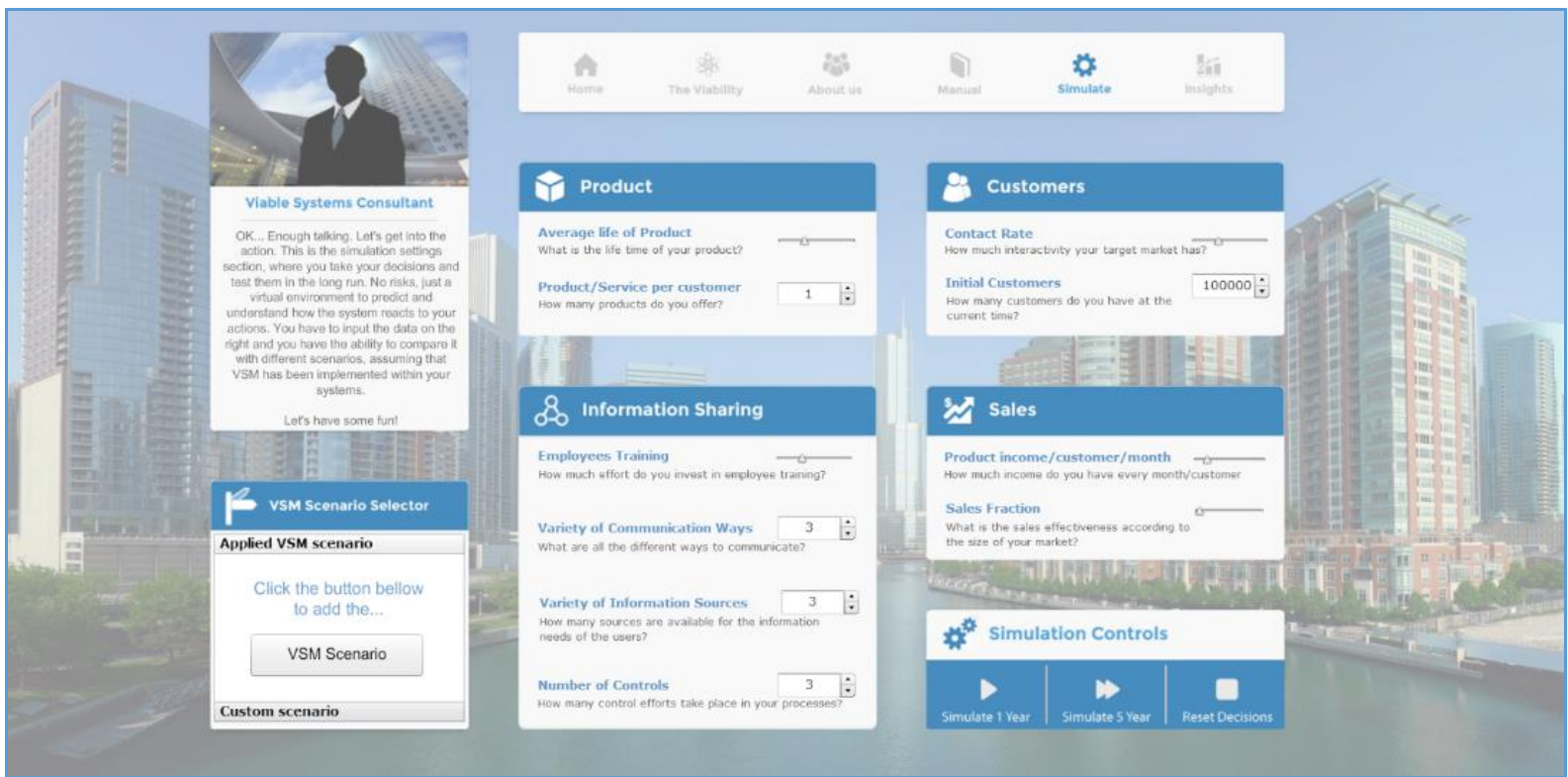

Figure 3 - The simulations Settings page

After the users have taken their decisions they use a fixed module in their interface that is solely used to control the simulation in terms of time progress. This module enables the users to simulate their scenario by 1 year, by 5 years or reset the decisions and try again.

\section{The Analysis}

The Simulation Analysis screen is where the decision makers will be prompted right after they select the time progress of the simulation run. It is what the web simulation is all about, since it enhances understanding about the complex behavior of the system under study.

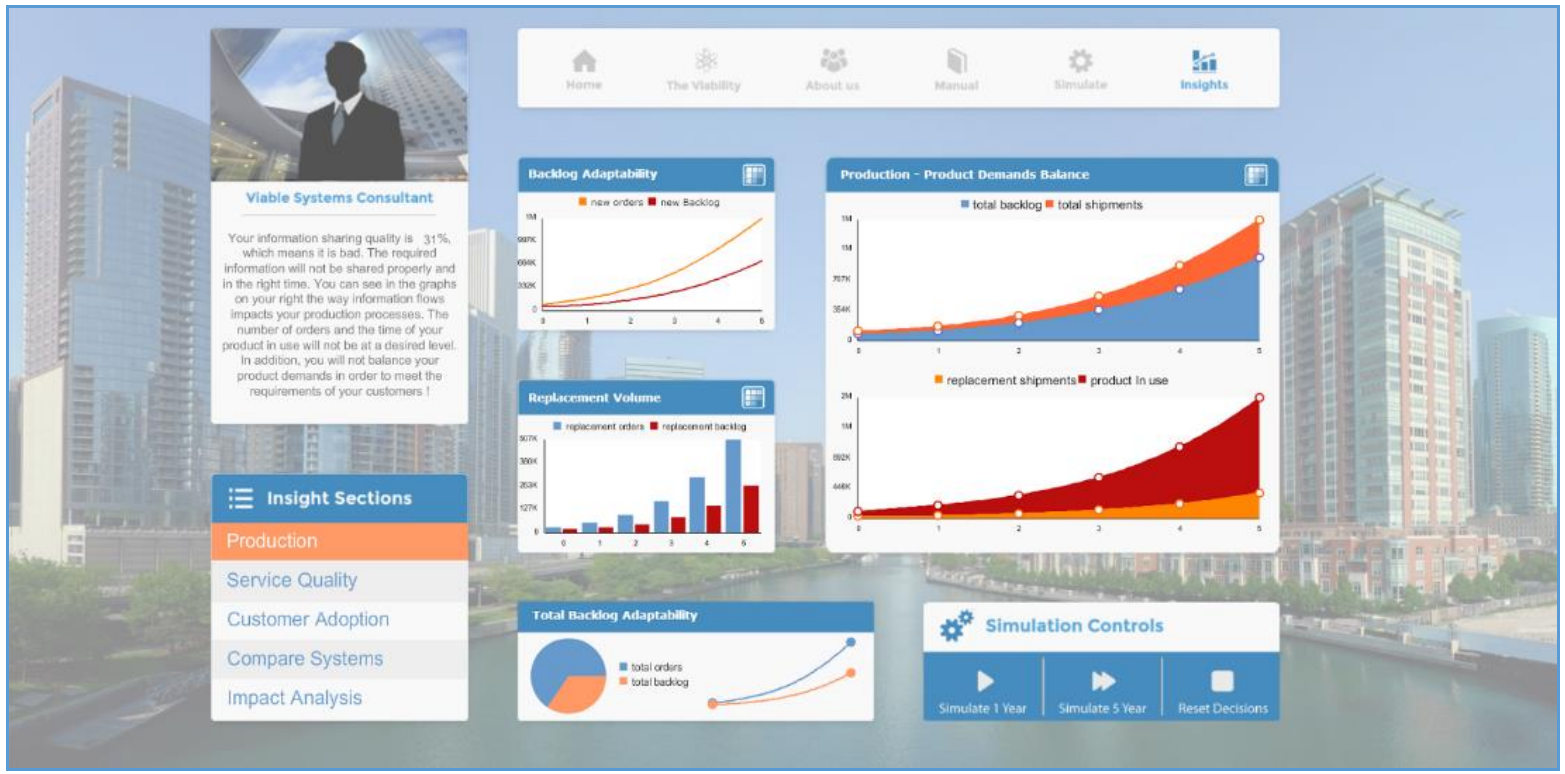

Figure 4 - The simulation's Insights Screen 
Automated analytics are provided by the system algorithms, the system dynamics model, the decisions of the current run and the selected scenarios for comparison with insights on Production, Quality of service, Customer Adoption as well as General System Metrics comparing to the VSM scenario. All the insights can be viewed both in a graph format as well as in a table format for a more detailed analysis of the results across the time period that the simulation run takes place (Figure 4).

The whole simulation ends up with the assessment section, which actually explains the decision makers how each decision affects the results that have been reviewed, what went wrong and why, what issues have appeared and provides suggestions on the changes that need to be made in the next simulation run to achieve better sustainability over the dynamics of the system towards achieving egovernance goals. This section is called Impact Analysis in the interface and supports the simulation user with VSM Visualizations that indicate problems and achievements as well as physical language descriptions and guidelines on how the "whole" has reacted to the decisions taken (Figure 5).



Figure 5 - The Impact Analysis Screen

The simulation provides an analysis in physical language, explaining to the user the results. Depending on the screen shown, the results calculated and the diagnosis, the "Viable Systems Consultant" will explain what happens in a specific module of the user interface. An example of its capabilities and what could be the output is the following:

"Your information sharing quality is X/10. The required information will not be shared properly and in the right time. You can see in the graphs on your right that the way information flows impedes your customer adoption. The number of potential customers that will finally be your committals is low. Additionally, your market share will not be effective at all because you will not meet your customer's requirements on time in contrast to the backlog adaptability. Maybe the VSM approach can handle things better here, as you can see in the graphs." 


\section{$5 \quad$ The Corfu Sunspots Agency's Simulation Scenarios}

When using the simulation consultant the user is able to import several variables' values to the simulation, which conclude to different outcomes.

A simulation scenario is illustrated here with some given variable values. The outcome from the dynamic simulation will help higher management to proceed with necessary changes and adjustments to the agency, in order to be productive and proactive.

The scenarios' main sections are:

- The Product Section

- The information Sharing Section

- The Customers Section

- The Sales Section

Product Section has two attributes. The average life of request/ticket (days) which is set to 5 days - if the request is due over 5 days then it does not need to be addressed - and the requests per customer which is 4 .

The Information Sharing Section has four attributes. The employees Training (\%) - set to 43 - is an information of the percentage of the training the agency gives to its' employees. The higher the training within the agency, the best the result in the daily processes. Moreover, the variety of communication channels and the variety of information sources the requests come from are part of the information sharing section. These attributes are set to 6 and 4 accordingly to the scenario. Additionally, number of controls - set to 5 in the scenario - depict how the controls are conducted.

Furthermore, the Customers Section include information of the requests daily rate along with the total customers. Both attributes are set to 250 and 100.000 according to the scenario.

Finally, the Sales Section depicts the total income per customer per month the agency may gain. To this example, it is set to $€ 200$.

\section{Production Insight Section}

The simulation yields the following outcomes (Figures $6-10$ ). For Figures $6-8$ and 10 the horizontal axis is depicting years.

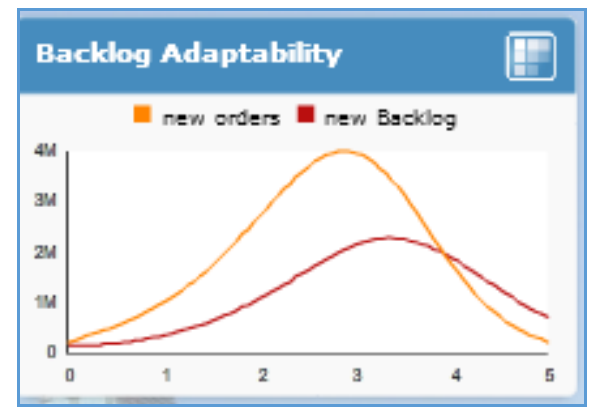

Figure 6 - Scenario Backlog Adaptability 
The backlog is getting higher. Requests are not served within the time limit of the 5 days and the sum of requests remaining open is getting large.

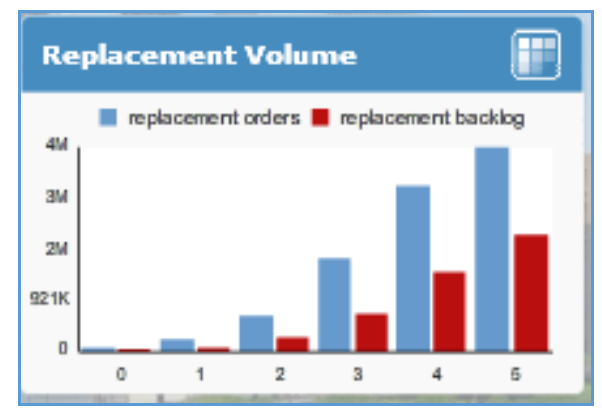

Figure 7 - Scenario Replacement Volume

The replacement orders of the unserved requests are increasing as well. Since the average life or request is reached, the requests are re-stated from the customers. Moreover, the same requests keep coming back, since they were not served along with the new ones.

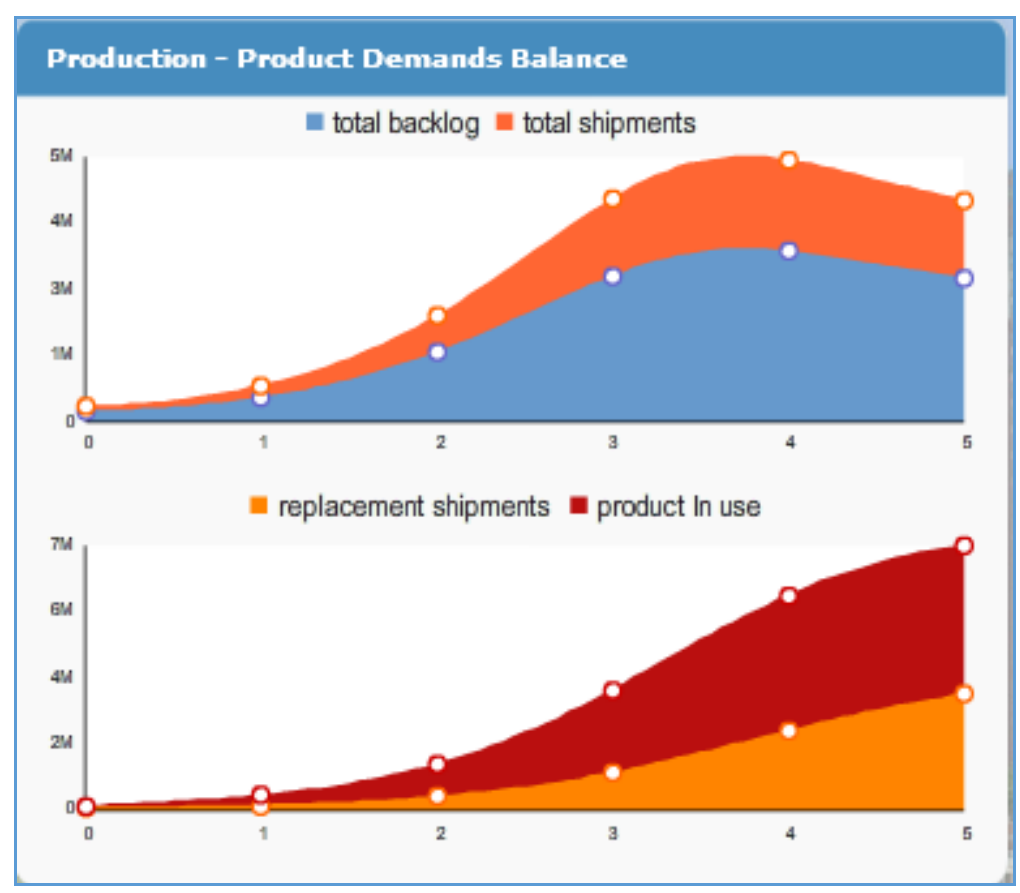

Figure 8 - Scenario Production - Product Demands Balance

The requests have a high replenishment rate and the service is not balanced.



Figure 9 - Scenario Total Backlog Adaptability 
Half of the daily work is devoted to backlog orders, since the increasing number of backlogged requests take half of the workday to the employees in order to be served.

\section{Service Quality}

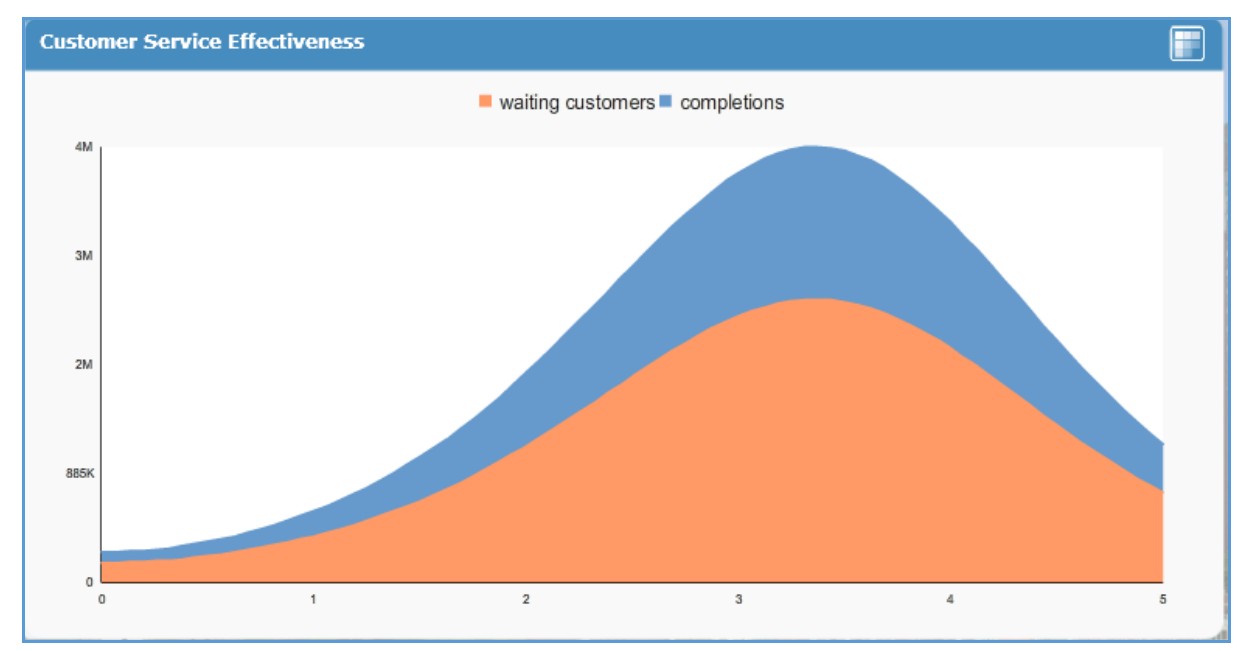

Figure 10 - Scenario Customer Service Effectiveness

In Figure 10 it appears that completions are few and waiting customers are many. Since the backlog of open requests is getting higher, the actual completions are few, the customers are waiting until they get served and the employees are not effective to the day-to-day work.

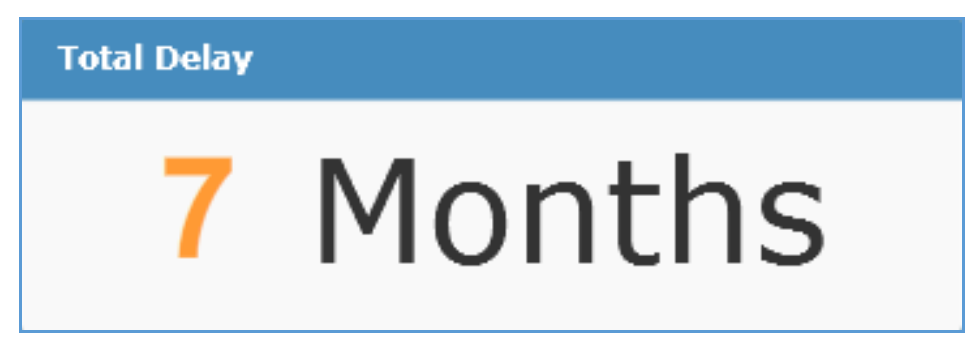

Figure 11 - Scenario Total Delay

With the given attributes, customers can have a total delay of 7 months until they are served (Figure 11). Since the requests in the tourist agency cannot wait that much until they are served, this is rephrased to lost customers.

\section{Customer Adoption}

There is no customer adoption, due to the big delay of getting served.

\section{Impact Analysis}

The impact analysis on the four basic factors determining the ISQ is the following.

\section{Employee Training}


Score $43 \%$ of the training the employees ought to have

The company has not invested enough in training its' employees on how to share information collaboratively and according to the company's' goals. This generated huge delays affecting the production and the service quality.

\section{Variety of Communication Channels}

Score 3 out of 10

The agency's employees actually do not know from which source they should dig the important information that they are responsible for. The agency through the training of the employees will enable them to handle the variety of ommunication channels and enable them to minimize the vulnerability of its' information system.

\section{Variety of Information Sources}

\section{Score 3 out of 10}

The company has not clarified how agents should share information, which means that everyone acts according to his/her judgement. It is most likely that the company's decision will create huge gaps in information sharing.

\section{Number of Controls}

Score 3 out of 10

The company's system does not apply adequate control processes for its complexity. This makes it vulnerable to human mistakes and creates uncertainty regarding the adaptability to the external environment.

\section{Viable System Consultant Outcome}

The online simulation model, using Viable System Consultant, provides some additional information regarding the simulation outcomes. Considering the scenario attributes, the Viable System Consultant yields the following:

"Your information sharing quality is $35 \%$, which means it is bad. The required information will not be shared properly and in the right time. You can see in the graphs on your right the way information flows impacts your production processes. The number of orders and the time of your product in use will not be at a desired level. In addition, you will not balance your product demands in order to meet the requirements of your customers! "(Figure 12) 


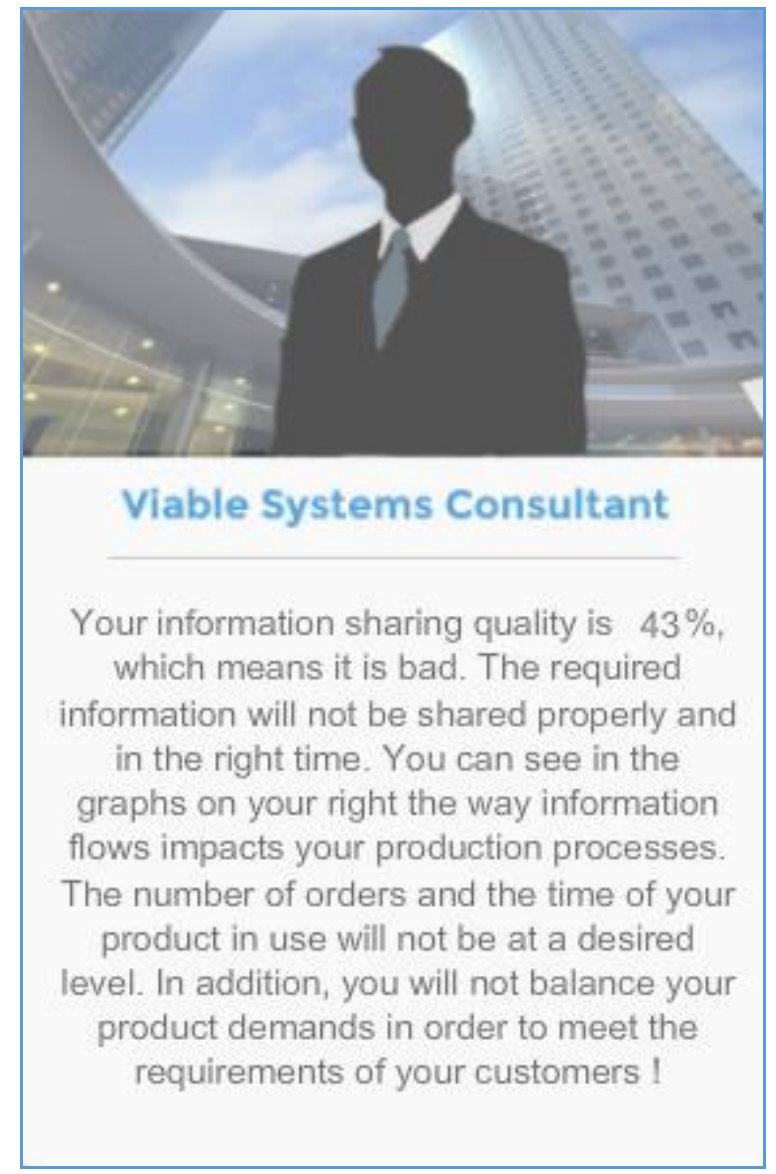

Figure 12 - The Viable Systems Consultant outcome

This outcome enables the management team running the simulation to make the necessary changes in order to get their company to provide a better service, less backlogged requests and better results. There was a deep impact to the company, since now all day-to-day requests are serviced and only a few cases remain backlogged. Considering that the ageny has 1000 requests to be serviced in a daily basis, before the redesign more than 200 requests were backlogged though after less than 30 remained unserviced. The employees are trained well in order to be productive and maintain the good service the company was known for. The good service is resolved to a few backlogged unserviced requests and less complaints for unserviced or wrong serviced requests.

\section{Conclusions}

This paper describes by the means of a case study the model that incorporated eG4M to the organizational structure and functioning of the tourism agency Corfu Sunspots using systemic methodologies and principles of the Viable Systems Approach Model for systemic interventions and improvements. It also provides a tool to business managers of how the changes implemented into their organization will resolve complex issues. The results help higher management into Corfu Sunspots Tourist agency be proactive, since they can adjust their company functioning according to the outcomes of the simulation and serve all their customers well. With the use of the simulation model the problem of Information Sharing Quality (ISQ) was defined and suggestions of how this problem could be resolved were provided. This is done in order the agency's management to create real time scenarios and according to the results delivered to decide the best approach to its daily processes. 
Systemic Methodologies are used to support the crucial role of human factor, which is the most important role of flexibility in terms of customer satisfaction and quality of provided services. The role of systems analysis in viability over a crisis period is crucial. The systemic redesign made the operation of the business more rapid, flexible and efficient in customer service, increasing the company's competitiveness in a highly dynamic changeable industry as it is the business of the tourism industry.

In conclusion, delays in servicing requests were decreased and backlogged requests were minimized. Therefore this resulted in getting the customers more engaged to the agency, having a small number of complaints and maintain/advance the high quality of its services.

\section{References}

Assimakopoulos N. (1988). The routing and cost of the information flow in a system, Systems Practice 1(3) (1988), p. 297-303.

Assimakopoulos, N., Theocharopoulos, I. (2009). Design and Control Systemic Methodology (DCSYM): a multi-agent modeling and operation platform. International Journal of Applied Systemic Studies, 2 (3), 193-217.

Beer S., 1972, Brain of the Firm; Allen Lane, The Penguin Press, London, Herder and Herder, USA

Corfu Sunspots Tourist Agency http://www.corfusunspots.gr - Retrieved June 20, 2017

Downs, A. (1967). Inside Bureaucracy, Scott, Foresman and Co., Glenview, Illinois, United States

Forio | Custom Simulations for Training and Higher Education, Retrieved June 20, 2017, https://forio.com/

International Teledemocracy Centre http://itc.napier.ac.uk/ - Retrieved June 20, 2017

K. D. Tocher, (1963). The art of simulation, English Universities Press

Lackner, M. R. (1962) Lackner, M. R. "Toward a general simulation capability", Modeling Concepts Extract: SIMPAC's Weltansicht in [AFIPS JCC 21] Proceedings of the 1962 Spring Join (1962) [AFIPS JCC 21] Proceedings of the 1962 Spring Joint Computer Conference in San Francisco, Ca. SJCC 1962

Law, A.M., Kelton, D.W. (1991). Simulation Modeling and Analysis. New York, NY: McGraw-Hill

Mason, R.O., Mitroff, I.I., (1981). "Challenging Strategic Planning, Assumptions:Theory,Cases and Techniques", NY, Wiley, ISBN 0-471-08219-8

Miaris A., Riggas A., Assimakopoulos N. (2013). "Strategic Systems Approach of Corfu SunSpots Travel during Economic Crisis", First Global Conference on Research Integration and Implementation, Canberra Australia, http://i2sconference.digitalposter.com.au/ - last accessed June 20th, 2017

Misuraca G. (2006). Meeting for the Launch of the Network of Innovators in Governance in the Mediterranean Region, 5 and 6 June 2006, Marseille, France, http://unpan1.un.org/intradoc/groups/public/documents/un/unpan031673.pdf - last accessed June 20th, 2017

Misuraca G., P. Rossel, M. Finger, (2006) Governance with and of ICTs: the need for new institutional design in a changing world, egov magazine, vol. 2, no. 5, May 2006.

Misuraca, G. (2007). e-Governance in Africa from Theory to Action: a handbook on ICT for Local Governance: Africa World Press / IDRC

Pendharkar P.C., Subramanian G.H., Rodger J.A., (2005). A probabilistic model for predicting software development effort, IEEE Transactions on Software Engineering, 31 (7), pp. 615-624

Vensim simulation software by Ventana Systems, Retrieved June 20, 2017, http://vensim.com/ 
Viscusi, G., Batini C., Mecella M. (2010). Information Systems for e-Government: a quality of service perspective, Berlin, Heidelberg, Springer

VSM Model, Retrieved June 20, 2017, http://en.wikipedia.org/wiki/Viable_system_model VSMod Software http://www.vsmod.org/ - Retrieved June 20, 2017 